

\section{ASPLUND, PEREGRINACIONES Y AÑOS DE PREGUNTAS} ASPLUND, THE YEARS OF WANDERING AND WONDERING Pablo López Santana

RESUMEN El movimiento Romántico Nacional se distinguió en Suecia de la misma corriente en otros países y del mero nacionalismo, al promulgar una visión del mundo progresista apostando por el cambio, en lugar de una visión inmovilista pastoral-agraria que lo caracterizaba como conservador en otros lugares. En su enfrentamiento con la industrialización y los nuevos estándares de vida a caballo entre los siglos XIX-XX, cristalizaron los movimientos liberales de enseñanza que posibilitaron las rupturas con la enseñanza académica imperante, hecho aprovechado por las vanguardias para erigirse como nuevo paradigma. En la situación de aislamiento de los países escandinavos, figuras como las de Asplund, Bergh o von Heidenstam aprovecharán la situación para sentar las bases de una conciencia nacional basada en las tradiciones, que articule la identidad de su pueblo ¿En qué medida sus estancias en el extranjero convirtieron este sentimiento de nostalgia en una necesidad vital? La obra de Asplund en relación a sus viajes ejemplifica el sentido que para un sueco supone estar lejos de su tierra así como la necesidad de reconciliación con sus orígenes que experimenta en su regreso al hogar, así como la aceptación parcial que el espíritu racionalista tuvo en la Suecia de la época. En el acomodo de influencias externas adquiridas en un lenguaje verdaderamente nacional se encuentran parte de las explicaciones a los enigmas que el trabajo de Asplund dejó suspendidos en el tiempo.

PALABRAS CLAVE Escandinavia, Romanticismo Nacional, Asplund, Viajes

SUMMARY The National Romantic movement in Sweden was distinguished from the same trend in other countries and from mere nationalism, by promulgating a vision of the progressive world and committing to change, instead of the ultra-conservative, pastoralagrarian vision characterized in other places. Its confrontation with industrialization and the new standards of life between the XIXth and XXth centuries, crystallized the liberal educational movements which enabled the ruptures with the prevailing academic line, a fact taken advantage of by the avant-garde to form a new paradigm. In the isolated situation of the Scandinavian countries, figures such as Asplund, Bergh or von Heidenstam, would take advantage of the situation to lay the foundations of a national conscience, based on traditions which articulated the identity of their people. To what extent did their stays abroad turn this feeling of nostalgia into a vital necessity? The work of Asplund, in relation to his journeys, exemplifies the sense that a Swede might have when far from his homeland, as well as the need experienced on his return home for reconciliation with his origins, and the partial acceptance of the rationalist spirit in the Sweden of that time. The explanations to the enigmas that the work of Asplund has left suspended in time lie partly in the adaption of acquired external influences in a truly national language.

KEY WORDS Scandinavia, National Romanticism, Asplund, Journeys

Persona de contacto / Corresponding author: santana@santanayvicente.com. Arquitecto. Escuela Técnica Superior de Arquitectura. Universidad de Sevilla. 
AZUL Y AMARILLO.

$\mathrm{L}$ a existencia de un estado no deja de ser un acuerdo de toda la gente, todos los días. Es decir: una abstracción supeditada a un consentimiento. Sin embargo, en la tradición secular, el concepto de nación es mucho más complejo, e indiferente a los dictámenes humanos. Su motor es la identidad nacional, que es sentimiento de individuo en el seno de un grupo. En Europa han coexistido dos modelos de "creaciones nacionales": uno el galo basado estrictamente en un acuerdo social que defina a la ciudadanía y, el otro, el bávaro en el que la afinidad y la costumbre consolidan a los miembros de la sociedad. Mientras que nosotros estamos familiarizados con el patrón francés, el alemán ha dado lugar al nacionalismo de Europa central y del este, y al de la Europa que para nosotros es la periferia del continente: Escandinavia'.

La nacionalidad como constructo social y cultural ligada unívocamente a una región, que ha llegado a nuestros días, tiene sus orígenes modernos en el siglo XIX. En el caso de Suecia, el retraso de la industrialización propició una inversión de valores: con la primera modernización en las décadas de 1880 y 1890, la menos "avanzada" sociedad sueca veía los aires depresivos que trajo el desarrollo industrial en la Europa de mitad del XIX (colapsos económicos, incremento de polarización de las políticas sociales, etc.), lo que propició un rechazo a la modernización desde sus comienzos, que marcó el arte nórdico del cambio de siglo ${ }^{2}$. Un arte profundamente local iba a ser visto como un camino de privilegiada universalidad, así la social-democracia que defendían los artistas suecos vinculó, como en ninguna otra región, el progreso y la defensa de derechos a las raíces y la recuperación de valores tradicionales, retroalimentándose ambas en el desarrollo artístico, arquitectónico y social de la época³. En este clima político-intelectual, las naciones nórdicas intensificaron su espíritu nacionalista y ofrecieron una nueva atención a las tradiciones autóctonas, estableciendo el devenir de las creaciones de los años venideros a través del movimiento llamado Romanticismo Nacional ${ }^{4}$.

1. Históricamente la diferencia entre los dos modelos se hace patente en los distintos requisitos para obtener la ciudadanía en Francia y en Alemania: mientras que cualquiera nacido en suelo francés era ciudadano francés, en Alemania sólo aquellos de parentesco alemán podían reclamar la nacionalidad. Cf. VON HERDER, Johann G.: Outlines of a Philosophy of the History of Man, Nueva York: Bergman Pub. 1973 (0.1880) y KOHN, Hans: The idea of nationalism: A study in its origins and background, NY: McMillan, 1944, pp. 330 y ss. Para una comprensión sobre el nacionalismo escandinavo ver el capítulo "Nationalism and scandinavianism" en DERRY, Thomas K.: A history of Scandinavia. Minnesota: Un. Minnesota Press, 1979. pp.: 220-249.

2. “...fue un buen momento, cuando la industria y comercio hacían muchos negocios y el dinero era tan abundante como la hierba y todas las personas querían comer bien. Entre 1872 y 1878, todo lo que uno escuchaba eran artículos de sindicalistas y órdenes de detención, billetes falsos y jubilaciones. Todo lo sueco estaba en sombra...". STRINDBERG, August: Röda rummet. Estocolmo: Bokforlaget Aldus, 1971 (0.1879). En el año en que Strindberg escribió su novela, unas revueltas sindicales socialdemócratas salpicaron al país, abrazadas por los artistas que sentían cómo los valores burgueses salvaguardados por las Academias imponían estéticas pasadas como dominantes.

3. En este sentido vid DRACHMANN, Povl: The industrial development and commercial policies of the three scandinavian countries, Londres: Oxford \& Clarendon Press, 1915. Para una comprensión de cómo las políticas progresistas estaban auspiciadas por la recuperación de valores nacionales ver VARNEDOE, Kirk: "Nationalism, internationalism and the progress of scandinavian art", en VARNEDOE, Kirk (ed.): Northern light. Realism and symbolism in scandinavian painting. NY: Brooklyn Museum, 1983. pp.: 7-26.

4. El movimiento también es conocido como Realismo Nacional o Naturalismo Romántico. Para un estudio del mismo vid MILLER, Barbara L.: National romanticism and modern architecture in Germany and scandinavian countries. Cambridge: Cambridge Un. Press, 2000. 


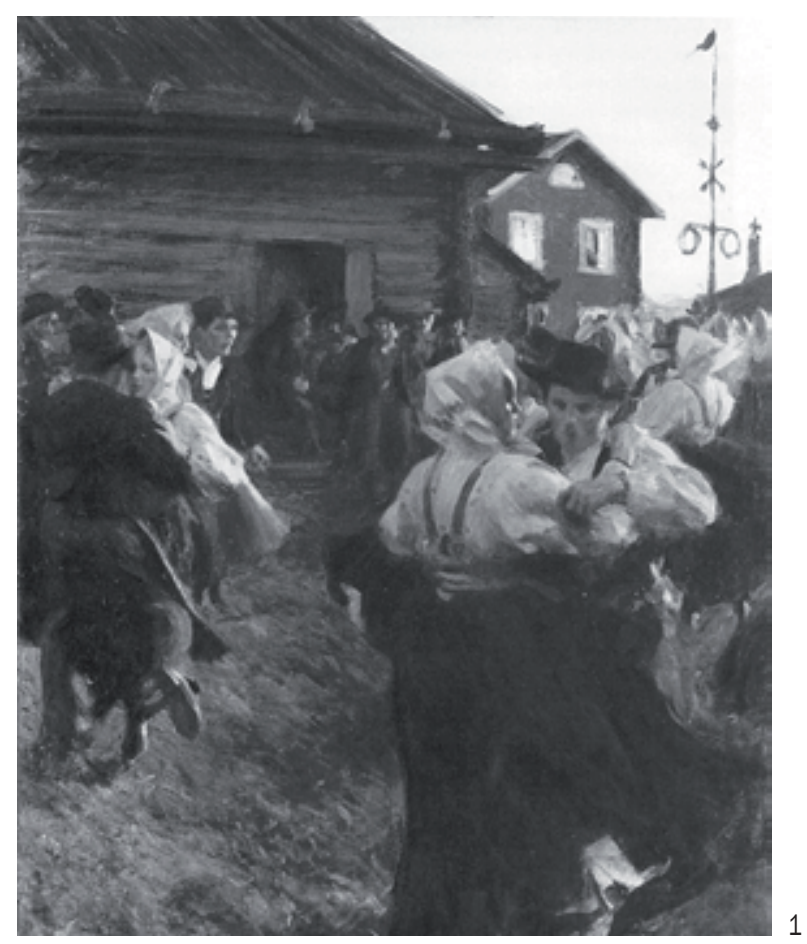

1. "Baile del solsticio" [Anders Zorn, 1897 (Nationalmuseet, Estocolmo)] “...el culto único de los suecos a la luz, su intoxicación de la danza, la intoxicación del amor...", en "Svenska själar pa förslag", Dager Nyheter, 27 de marzo de 1993, p. 17. El periódico sueco mantuvo un concurso donde el cuadro de Zorn de su región natal de Dalarna fue nombrada la obra de arte "más" sueca de la historia.

2. "San Jorge y el dragón" (Carl Larsson, 1886 - Catálogo de exposición del Sindicato de Artistas). Muestra el edificio de la Real Academia de Bellas Artes bajo una mujer con el cartel "el arte sueco aún privado de libertad" Blandiendo la espada del sindicato y llevando una paleta a su espalda, "San Jorge" ataca al dragón de la academia, quien ha sido ya alcanzado por una lanza que lleva inscrita la palabra "oposición".
Para comprender las bases del movimiento es imprescindible un conocimiento más o menos profundo de la idiosincrasia sueca, el espíritu nórdico y los valores que han caracterizado a la cultura del norte ${ }^{5}$, especialmente, para sentir cómo esta corriente sólo pudo nacer en Escandinavia y, concretamente, en el cambio de siglo. Tres son los pilares que sustentan al Romanticismo Nacional: el concepto de habitus vincula el sentimiento nacional al ambiente nativo, creando una simbiosis entre el habitante y la tierra natal: una tierra que es naturaleza originaria y esculpe el temperamento nacional; la búsqueda del rettferd arraigada en el sistema de valores suecos en forma de equidad, humildad y sentido colectivo ${ }^{6}$ (aquí es donde se encuentra con el activismo social); y la nostalgia del hemlägtan (anhelo al hogar) que suspira eternamente el que está lejos por regresar al regazo de los otros dos valores. La lejanía, así, exalta visceralmente estas tres dimensiones: potencia la nacionalidad del sueco. De esta forma, el viaje para el nórdico subvierte su prolíica misión y, el aparente influjo internacional, se convierte en despertar nacional ${ }^{7}$ (figura 1)

El viaje ha sido complemento por excelencia de la formación artística y técnica del individuo occidental y, en los siglos que antecedieron al XX, la dificultad en el trasvase de información lo convertía en imprescindible para quien gustara de ofrecerse moderno, trasladando a su tierra las últimas corrientes extranjeras. Frente a esta necesidad, la posición de aislamiento de las naciones nórdicas respecto al continente situaba a sus habitantes al margen de cualquier flujo intelectual en comparación con el resto de las naciones y, así, pocas de ellas tienen una mayor tradición errante que la sueca: desde Santa Brígida a sus héroes nacionales todos terminan cruzando el Báltico8.

La formación en la Suecia del XIX estaba anclada en el academicismo europeo. El estado becaba a sus estudiantes con viajes a Europa al final de su formación académica: Roma había sido su Meca hasta 1848 y, entre 1850 y 1865 , todos peregrinaron a Dusseldorf o Múnich hasta que las políticas bélicas de los germanos hicieron que los patrocinios del rey Karl XV mirasen a París, cuna de la modernidad europea, hasta el cambio de siglo9.

\section{PARALIPÓMENOS EN ASPLUND}

Gunnar Asplund vino al mundo en Estocolmo en 1885, coincidiendo con el regreso definitivo del periplo parisino de Carl Larsson y dos años antes del de Verner von Heidenstam. En concreto un veintidós de septiembre, una semana después de la inauguración de la exposición "Opponenterna" (Los Oponentes) en el Salón Blanch de París ${ }^{10}$, que precipitó la formación por parte de Bergh del paraoficial Sindicato de Artistas: algo más que la serendipia puede justificar tal alineación de acontecimientos y su influencia en la personalidad y vida de Asplund. Como recuerdo hipnótico, años más tarde, tras completar sus estudios en el KTH de Estocolmo y, al considerar desfasadas las enseñanzas y metodologías de la Academia Nacional, un puñado de oponentes -liderados por Asplund- abordaron a los arquitectos más influyentes de 


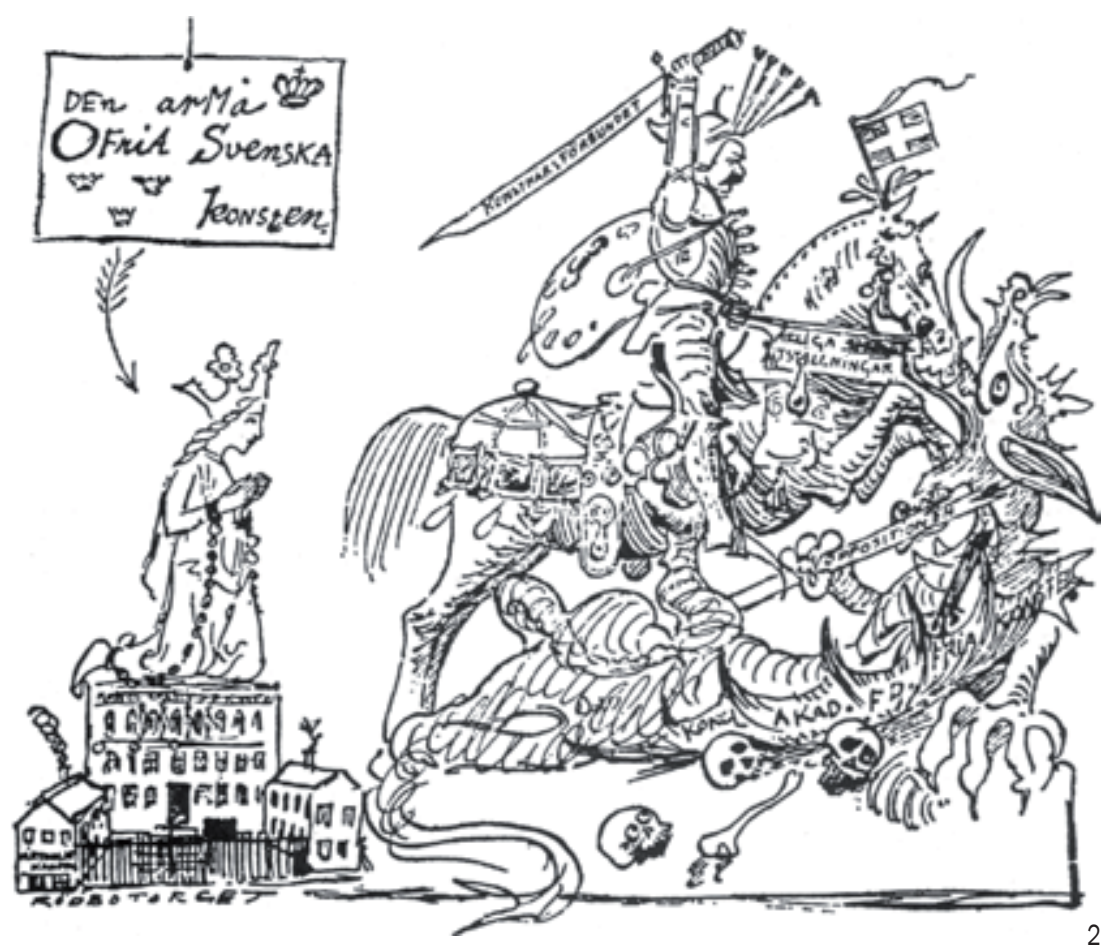

la época para que fueran sus tutores en la liberal Klara Skola, emulando el proceso de ruptura que anteriormente habían protagonizado sus compatriotas artistas de la colonia nórdica en París ${ }^{11}$. Muy probablemente la Klara Skola fue el acontecimiento que diferencia a los dos viajes de estudios más conocidos de Asplund: el oficial y estatalmente becado viaje a Alemania y Bélgica en 1910 para el estudio de un nuevo material de revestimiento, y el autofinanciado viaje a Italia y Túnez entre 1913 y 1914 , más experimental que académico. Entre ellos, en el verano de 1912, recorrió todo su país natal ${ }^{12}$ (figura 2).

El carácter de su viaje al sur, por libre y a la medida de sus inquietudes personales, provocó que sólo nos hayan llegado los dibujos y anotaciones que Asplund hizo en sus cuadernos y no los informes que reclamaba el estado al patrocinar una estancia, lo que, en cierto modo, nos ha permitido comprender las verdaderas preocupaciones que, más adelante, fueron desarrolladas a lo largo de su

5. Vid KENT, Neil: The soul of the north. A social, architectural and cultural history of the Nordic Countries. Londres: Reaktion Books, 2001 (0.2000).

6. Para una explicación del determinismo geográfico del habitus en el que creían los artistas suecos de la época vid FACOS, Michelle: Nationalism and the nordic imagination. Swedish art of the 1980s. Londres: Un. California Press, 1998. pp.: 28 y ss. Reflejado en los nombres más comunes suecos relacionados con su naturaleza: Björn (oso), Dag (día), Stig (sendero), Englund (pradera de bosques), Alström (corriente de arroyo), Dalgren (valle de pinos) 0 Lagerlöf (hoja de laurel), Por otro lado, aunque la palabra rettferd es noruega, el término se emplea en la cultura sueca. Cf. DAHL, Hans F.: “Those equal folk”, en Daedalus. 1984. Oslo. vol. 113, n`1 $^{\circ}$ p. 95.

7. La actitud de los nórdicos ante el viaje se refleja en la anécdota apócrifa de los dos artistas suecos que se encuentran en la vuelta a casa de sus periplos por Francia e Italia: “¿Qué hiciste en Italia?”, le pregunta el parisino, "Aprendí, entre otras cosas, a amar a Suecia”. (Narrado en JOSEPHSON, Ragnar: Nationalism och Humanism, Estocolmo: Bonnier, 1935. p. 112).

8. Referido a la novela de Verner von Heidenstam de 1901, Helliga Brigittas pilgrimfard (La peregrinación de Santa Brígida).

9. En 1864 las tropas alemanas de Bismarck invaden Dinamarca, aunque este hecho fuese detonante para el cambio de destino, el matiz de que Karl XV fuera primo segundo materno de Napoleón III, emperador de Francia, no debió ser baladí. Según Braun, la migración a la capital francesa vino provocada por la humillación que recibió el arte nórdico en la exposición de París de 1878 (BRAUN, Emily: "Scandinavian painting and the french critics", en VARNEDOE Kirk (ed.): Op. cit. pp.: 67-75).

10. FACOS, Michelle: Op. cit. pp. 16 y ss.

11. Para la ruptura con las Academias estatales vid LINDWALL, Bo: Artistic revolution in nordic countries. En VARNEDOE, Kirk (ed.): Op. cit. pp.: 35-42. Para el proceso de formación de la Klara Skola vid LINN, Björn: "Gunnar Asplund och det Nordiska Ljuset" en AA.VV.: Asplund, 1885-1940. Arsbok. Estocolmo: Arkitekturmuseet, 1986. pp.: 78-93. Para la colonia de artistas nórdicos en París vid HEDSTRÖM, Per: “Les beaux-arts en Suède de 1870 à 1914 ” en SCOTEZZ DE WAMBRECHIES, Annie (ed.): Echappées nordiques. Lille: Palais des Beaux Arts-Somogy, 2008. pp.: 141-211.

12. Además de estos viajes y los que tuvo que realizar por motivos laborales, visitó en varias ocasiones los países escandinavos con sus alumnos de la Escuela Tecnológica. En este sentido, vid ENGFORS Christina: E.G. Asplund. Architect, friend and colleague. Lalholm: Arkitektur Förlag, 1990, pp.: 99-107. 
Así, las notas, dibujos y bocetos de Asplund en su estancia por el Mediterráneo evidencian un interés tanto en el tratamiento de las superficies como de los motivos decorativos y de ornato: no sólo dibujó fachadas, esculturas y fuentes, sino despieces de carpinterías, grabados, murales, mosaicos, detalles de labra... dotándolos de significado en su obra posterior. En este orden, la pintura mural, así como el embellecimiento de los edificios mediante la inclusión de experiencias artísticas en ellos, había sido empleado por pintores del Romanticismo Nacional como Carl Larsson o Prins Eugen para infundir un espíritu autóctono a finales del XIX mediante temas de naturaleza y tradición sueca. De esta forma, la labor de Asplund con las superficies que es manifiesta en la integración de otras disciplinas artísticas en sus edificios (mediante pinturas murales, frisos y escayolas) como en el propio tratamiento del espacio en tanto forma y policromía, tiene una doble vertiente originaria: la de una reafirmación de principios oriundos inherentes al arte sueco a través de lo experimentado en el extranjero ${ }^{17}$ (figura 3).

\section{Cine Skandia.}

En el cine Skandia, que conceptualmente no deja de ser un espacio doblemente interior (una caja dentro de una caja), el tratamiento cromático del techo le permite una ambigüedad espacial que rompe la relación binaria interior-exterior: la obscuridad de la bóveda que cubre la sala de proyecciones, permite entenderla como un cielo anochecido en el que aparecen La Luna de Gunnar Torhamn (el altavoz) y las luces suspendidas como corte celestial. En sintonía con la recuperación de los valores románticos, Asplund trabajaba con la arquitectura y la naturaleza intercambiando motivos sin dejar de representar la dualidad básica que su oposición simbolizaba según los parámetros tecnocráticos de la industrialización más ferviente. ${ }^{18}$ Así, los espectadores, que van adentrándose progresivamente en la ambientación pantagruélica creada por Asplund a través de un cuidado sistema procesional, al finalizar su recorrido y tras pasar la calle que penetra en el vestíbulo mediante el pavimento; la rotonda de las estrellas que anticipa el tema del cielo de la sala final; la Vía Láctea de Engström sobre las escaleras y elegir penetrar por una de las misteriosas puertas rojas que sobresalen en los antepalcos, embocan una sala de proyección donde, mediante el recurso atectónico de hacer desaparecer el techo mediante el color obscuro empleado, Asplund elimina referencia alguna de altura, lo que le permite introducir elementos deliberadamente fuera de escala y de posición que modifican las proporciones de la sala en lo que se ha llamado ausencia de distancia ${ }^{19}$. El origen de la arquitectura Asplund lo encuentra entre lo construido y el cielo suspendido en las alturas, en el

13. Para este tipo de lecturas en su obra vid WREDE, Stuart: La arquitectura de Erik Gunnar Asplund. Barcelona: Júcar Universidad, 1992 (0.1980). 14. FANT, Ake: “Nagra aspekter pa Stockholmsutställningen 1930”, en AA.V.:: Asplund, 1885-1940. Arsbok. Ed. cit. pp.: 66-77.

15. Cf. MATTSON, Helena y Sven 0. WALLENSTEIN: 1930-1931. Den svenska modernism vid vägskälet. Estocolmo: AXL, 2009.

16. Asplund se casa con Gerda Sellman y, en otoño de 1918, recorre Dinamarca en bicicleta. En la isla de Mon visitó Hytten (la cabaña) influyéndole notablemente. Vid ASPLUND, Erik G.: “Literatur, Liselund”, en Arkitektur. marzo de 1919. Estocolmo. pp.: 45-46.

17. “...un cielo claro y profundo con tal tonalidad en su color que constantemente estoy imaginando el cielo como una vasta cúpula pintada de azul..." Asplund sobre Túnez (03-03-1913) MORENO MANSILLA, Luis (ed.) Op. cit. p. 313. Mientras que la mayoría de sus contemporáneos en sus viajes por el Mediterráneo destacaban la blancura de las superficies (como Le Corbusier o Adolf Loos), la insistencia de Asplund en el color es uno de los aspectos que hicieron su estancia en el sur diferente. Sobre la policromía en la obra de Asplund vid LYN, Francis E.: "Mediterranean resonances in the work of Erik Gunnar Asplund" en LEJEUNE, Jean-Françoise y Michelangelo SABATINO (eds.): Modern architecture and the vernacular dialogues and contested identities. Nueva York: Routledge, 2010. pp.: 213-230. Además, la creencia de la influencia positiva que un edificio "bello y coloreado" tiene sobre la persona había calado tan hondo en la sociedad sueca que, un decreto parlamentario de 1897 (aún vigente en nuestros días) estableció que el 1\% de los presupuestos para edificios públicos fueran dedicados al embellecimiento artístico, lo cual explica la colaboración que Asplund mantuvo en toda su obra pública con diversos artistas suecos de la época.

18. Aalto y Asplund tuvieron su primer encuentro en el Cine Skandia: “...tuve la impresión de que esta era una arquitectura en la que los sistemas ordinarios no habian servido de parámetros. Aqui el punto de partida era el hombre, con todos los innumerables matices de su vida emocional, y la naturaleza" AALTO, Alvar: "E.G. Asplund in Memoriam”. En SCHILDT, Göran (ed.): De Palabra y por Escrito. El Escorial: El Croquis, 2000 (0.1940), p. 334. El propio Aalto reconoce la influencia notable en la época del Skandia en su artículo de 1928 (AALTO, Alvar “Un Cine Racional”. En SCHILDT, Göran. (ed.) Op. cit. (0.1928), p. 92).

19. CORNELL, Elias: “El Cielo como una Bóveda”, en ALHBERG, Hakon: Gunnar Asplund, Arquitecto. 1885-1940. Madrid: COAAT, 1982 (0. 1961$)$ p. 83. 
Biblioteca Nacional.

Adán y Eva, en un reconocimiento al origen de la humanidad en el seno de la naturaleza (de esa naturaleza ontológica de la que habla la sala), flanquean la pantalla del cine así como las puertas (en los tiradores) de la Biblioteca Nacional donde aparece el grabado presocrático gnóthi seauton como advenimiento del interior ${ }^{22}$. El nacimiento del hombre y la necesidad de conocer sus condiciones conducen a aquellos que buscan el saber en un nuevo peregrinaje al que Asplund obliga a quién pretenda alcanzar el Conocimiento. En una concepción egipcia del edificio (en tanto arquitectura como dirección ${ }^{23}$ ), Asplund, en adscripción gnóstica, concede a la Biblioteca - al camino - la posición del esfuerzo obscuro que es necesario recorrer para llegar a la salvación del conocimiento en la sala de los libros: lugar donde se acumula el saber, donde los libros se deslizan sobre la superficie curva de la sala de préstamos (de nuevo un espacio doblemente interior: un cilindro dentro de un prisma) ante nuestra mirada sin que podamos tocarlos, en alusión a la imposibilidad de alcanzar el conocimiento absoluto: el conocerse a uno mismo.
Aunque la Biblioteca Nacional es consecuencia (parcial) de un viaje por Alemania, Inglaterra y los Estados Unidos para el estudio del funcionamiento de estos - para la época - nuevos edificios ${ }^{24}$, es destacable la subordinación del elemento constructivo - mediante su disposición, al contenido fundamental de la obra: los libros y el saber, ya que, en principio, la forma cilíndrica no parece la más recomendable para hacer descansar a las estanterías. En cualquier caso, en el contrato entre el círculo y el cuadrado se encuentra las formas geométricas fundamentales, una especie de enfrentamiento entre los instintos primitivos y la razón evolucionada que tanto se debatía en época romántica. El camino hacia la sala es también un juego de claro-obscuros: El vestíbulo de paredes de ocho metros de altura de estuco negro, con los pasajes de La llíada esculpidos por Johnsson ${ }^{25}$, deja vislumbrar la luz emergente del fondo del camino. Los arranques de las escaleras laterales que rodean al cilindro (como si se hubieran trasladado directamente del cilindro de la sala de justicia del Tribunal de Lister y paralelamente a la propuesta de hall circular para el Tribunal de Göteborg ${ }^{26}$ ) confieren el último

20. Para un desarrollo del término vid MORIN, Edgar: El hombre y la muerte. Barcelona: Kairós, 2007 (0.1951) pp. 95-96.

21. La introducción por parte de Asplund de elementos decorativos propios de figuraciones clásicas ha producido controversias a la hora de analizar su obra, Ilegando a calificarla de superflua (ZEVI, Bruno: Erik Gunnar Asplund. Buenos Aires: Infinito, 1957. pp. 17-18). Sin embargo, atendiendo a la intención festiva del arquitecto, a sus alegres referencias italianas, podemos entender el proyecto como una reinterpretación de una escena urbana más propia del carnaval donde los elementos adquieren un significado en el conjunto, sin rehuir de lo banal que encierra la propia celebración recreada.

22. Asplund dibujó las figuras de Adán y Eva en su visita a la Catedral de Monreale en Palermo el 12-02-1913 y el aforismo Gnóthi Seauton (Conócete a ti mismo) del museo de las termas de Pompeya el 19-03-1913. Sin embargo, August Strindberg en su obra El Viaje de Pedro el Afortunado (18) ya toma este principio presocrático. Según el gusto que Asplund y su segunda esposa Ingrid Hindmarsch que tenían por la obra de Strindberg, sobre la que volvían una y otra vez (vid WREDE, Stuart: Op. cit., p. 238) es del todo improbable que desconocieran el contenido de la obra.

23. Oswald Spengler en su libro de 1918 Der Untergang des Abendlandes (La Decadencia de Occidente) se refiere al concepto cultural egipcio del espacio como dirección (camino), cuya representación venía dada en los templos de caminos laberínticos dirigidos hacia una meta, en alusión al infinito. Asplund conocía sobradamente este libro, ya que lo nombró en numerosas ocasiones en su discurso de acceso al KTH de 1931 "Var arkitektoniska rumsuppfattning". Para el predominio del carácter egipcio de la propuesta respecto al romano o al griego vid ALHBERG, Hakon: Op. cit., p. 37 o WREDE, Stuart: Op. cit., pp. 124 y ss. 24. En este sentido vid BLUNDELL-JONES, Peter: Asplund. NY: Phaidon, 2006, pp. 111 y ss.

25. La llíada es atribuida a Homero y está concebida como la primera obra de la literatura occidental, por lo que este motivo ahonda más en la concepción del edificio como camino hacia el saber: en la entrada (en el comienzo) la obra madre de occidente, junto al principio presocrático Gnoti Seafton constituyen el origen del saber. Continuando la tradición sueca de la pintura mural y la inclusión de artes plásticas en la arquitectura numerosos artistas colaboraron con sus obras en la Biblioteca: H. Linqvist, N. Sjögren, A. Munthe, o N. Dardel entre otros.

26. Aunque en su viaje para el estudio de bibliotecas conoció la sala de lectura circular del British Museum y los espacios centrales de las bibliotecas de A. Kahn de las universidades de Minnesota y Michigan, existían referentes formales que pertenecían al imaginario nórdico emergente en la época como la Sede Central de la Policía en Copenhague (1918-24) de A. Rafn y H. Kampmann. Para la influencia en los años 20 de la arquitectura danesa sobre la sueca vid PORPHYRIOS, Demetrios: "Reversible Faces" En Lotus International, n 16, septiembre de 1977. Londres. pp.: 35-41. Para un estudio pormenorizado de la propuesta con hall circular del Tribunal de Göteborg en el seno de todas las que tuvieron lugar entre 1913 y la definitiva de 1936, vid LÓPEZ-PELÁEZ, José Manuel: La Arquitectura de Gunnar Asplund. Barcelona: Fundación Caja de Arquitectos, 2002. 
5. Arriba: Exposición de Arts\&Crafts (Hakon Alhberg, 1923, Göteborg). Abajo: Biblioteca Nacional (Gunnar Asplund, 1918-27, Estocolmo) “....un templo necesita altura: el esfuerzo de ascender a él infunde respeto. La alta base como una escalera aumenta esta impresión a medida que penosamente se asciende..." Asplund sobre los templos de griegos de Sicilia (15-02-1914).
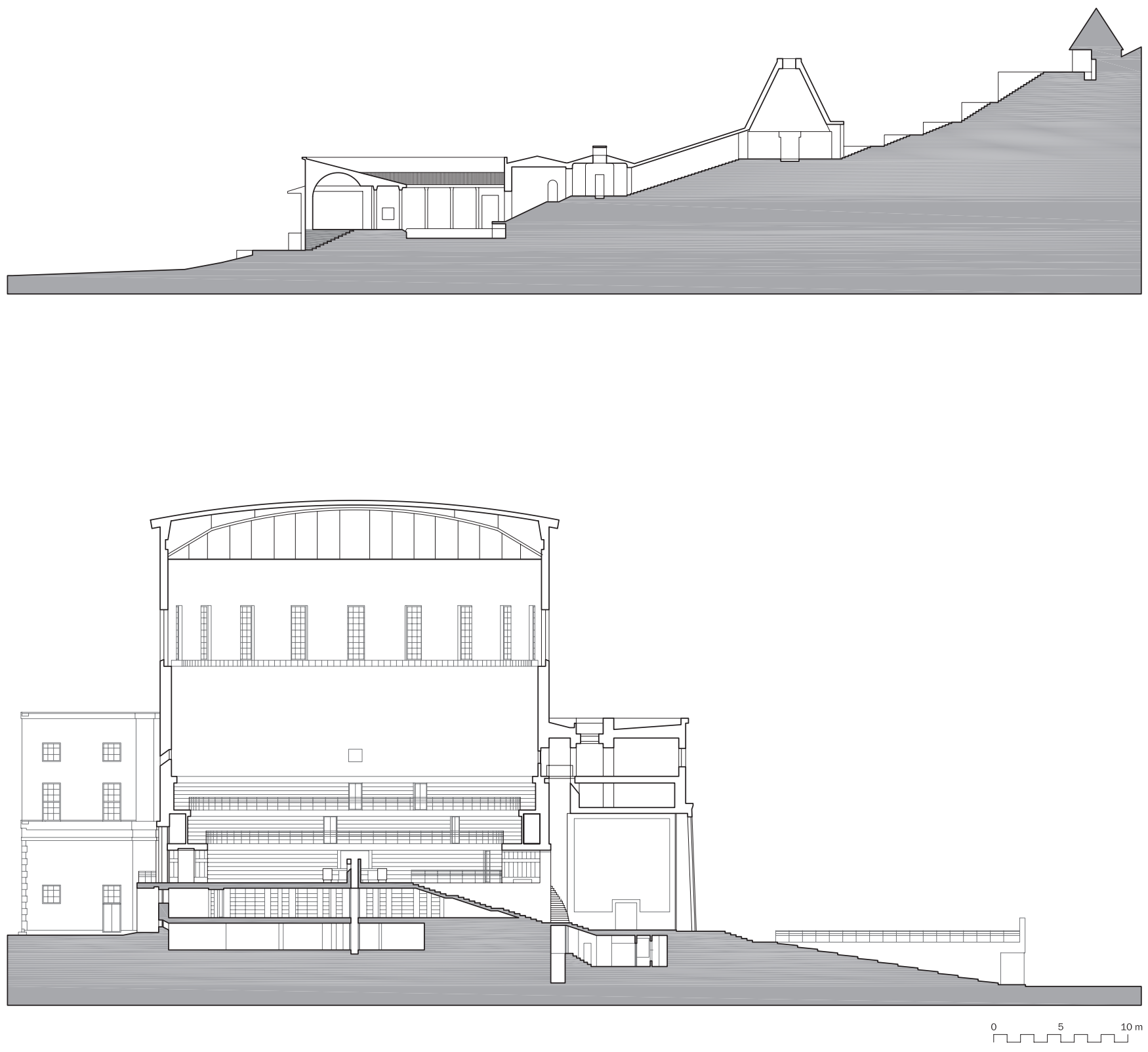
enigma por el que debemos elegir nuestra dirección. La estrechez y obscuridad de las mismas (que sirven para el personal de servicio) les confieren un misterio indescifrable: como en el telón que deja intuir la pantalla del cine Skandia, como en tantas otras cuestiones un juego de mareas entre lo conocido y lo desconocido que no nos será descubierto. Una vez acometidas las escaleras centrales se abre el espacio: Si en el Skandia el tratamiento de las superficies y la pérdida de escala en el espacio se hace mediante el color, en la Biblioteca, el color (blanco) da paso a la luz, que, en la claridad provocada presenta el conocimiento de la humanidad, desmaterializando la pared circular, que en su comprensión de la luz nórdica, cerraba al cilindro del saber (figura 5).

\section{Cementerio del Bosque}

La luz creada en la sala de préstamos de la Biblioteca Nacional aumenta el efecto dramático al contraponerse a la obscuridad de la entrada que enciende el misterio que abre el recorrido. El efecto de la luz en superficies curvas ya lo había experimentado con anterioridad -sin llegar a un resultado que le resultara satisfactorio- en la Capilla del Bosque, donde una vez más está recogida la idea del recorrido, en este caso, directamente por la naturaleza del bosque de abetos ${ }^{27}$. Aunque el homenaje romántico se presenta desde el lema con el que titulan la propuesta él y su compañero de la Klara Skola, Lewerentz (Tallum procede de latinización de bosque de pinos y una ligerísima transformación fonética del nombre de una villa romántica de Wahlmann, que era miembro del jurado del concurso) ¿Existe algo más sueco que un bosque de abetos? A pesar de que ha sido argumentada la conexión de la propuesta con el cuadro de Bocklin Die toteninsel y con la obra de Friedrich ${ }^{28}$, la afinidad con la obra de Liljefors y, muy especialmente con Skogen de Prins Eugen, marca una directriz pro- fundamente nórdica tanto en concepción como en figuración: si el paisaje es alma del habitus sueco, el movimiento romántico en arquitectura con su interés por el pasado y sus construcciones autóctonas dotan de un contenido emocional a la obra que puede convocar a von Heidenstam o Strindberg. Así, su visita a la isla danesa de Mon y su recorrido por la geografía sueca le proporcionaron el bagaje imaginario de la arquitectura vernacular que ejecutó en la Capilla del Bosque, donde la solución atectónica de la desmaterialización en este caso llega a través de la propia naturaleza, la prosopopeya de la propia obra ya que la luz del interior acoge el final del recorrido mortuorio que, a través de la configuración formal del edificio y su entorno, alberga espacios de ambigüedad interior-exterior como el pórtico de entrada, ¿Pertenece al bosque o al edificio? ¿Son pilares o troncos de árboles? La capilla apunta hacia la ontología de la construcción, de la geometría y de la nacionalidad: construyendo una cabaña (mediante una pirámide y una esfera) que fuera monumento en el que se reconociera la propia cultura del país en su naturaleza, en su doble acepción: como esencia y propiedad característica de cada ser y como conjunto, orden y disposición de todo lo que compone el universo. Punto local de partida, esta obra disfruta de un campo mucho más amplio. Como ejercicio artístico, el resultado final pertenece a un ámbito mayor que el de la fuente original: de esta forma es posible comprender obras como la Capilla del Cementerio de Kvarnsveden de Lewerentz (1919-24), el interior de la Neue Wache de Tessenow (1945) o la escena final de Ordet de Dreyer (1955). Es decir, como le ocurriera a Asplund en sus viajes y su vida intelectual, la Capilla trasciende de su origen local y disciplinar (como símbolo nacional y templo arquitectónico) para influir en el imaginario de la arquitectura extranjera y otras artes nacionales (figura 6). pp.: $41-46$. 

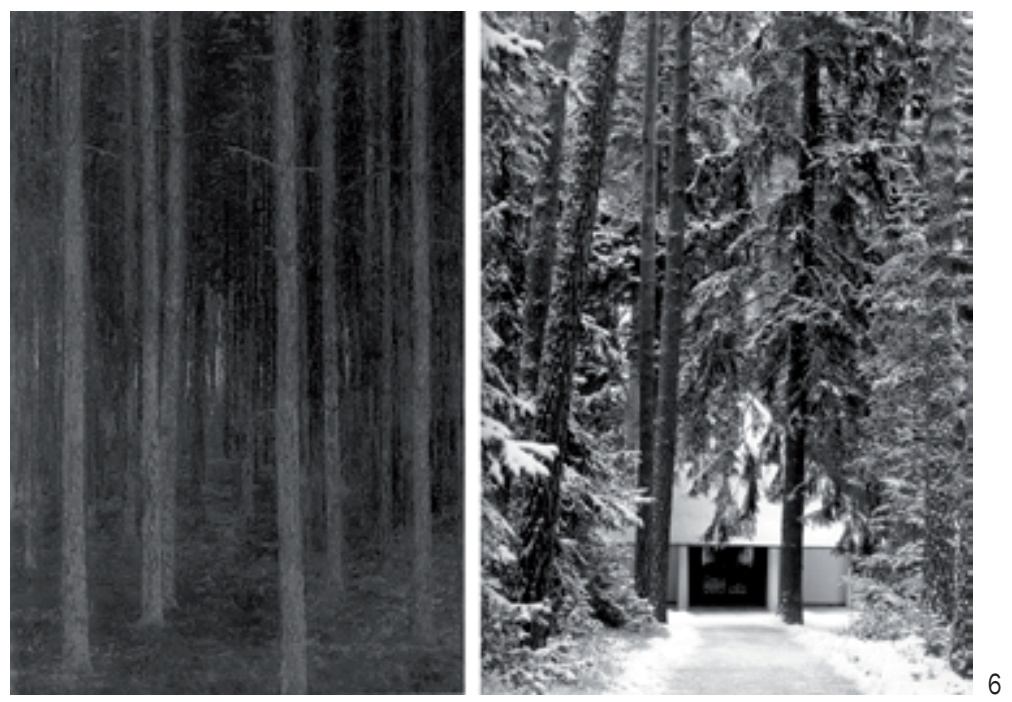

6. Izquierda: "El bosque" (Prins Eugen, 1892, Göteborgs Konstmuseum). Derecha: Capilla del Bosque (Gunnar Asplund, 1918-20, Estocolmo). “.... El bosque susurra! jEl bosque susurra! Moradas están ahora tus piñas, abeto poderoso, y eso te realza, árbol magnífico (...) él apartaba las ramas negras que entorpecían la marcha. Los abetos alcanzaban tan gran altura, que sus copas se balanceaban en otro mundo muy diferente..." Skogen susar (El bosque susurra) de von Heidenstam (1904). 7. Arriba: Capilla del Bosque (Gunnar Asplund, 1918-20, Estocolmo). Centro: Tribunal de Lister (Gunnar Asplund, 1919-21, Sölvesborg). Abajo: Casa de verano (Gunnar Asplund, 1937, Stennäs). El círculo y el cuadrado se encuentran en muchas de las plantas de Asplund. A finales de su carrera, este encuentro se desliga de la cuestión formal.

\section{Casa de Verano en Stennäs}

La capilla deudora de la arquitectura doméstica tradicional nórdica; el bosque de abetos del imaginario escandinavo; la luz del interior es fuego desde el exterior, se convierte en la luz crepuscular del norte... el fuego y la construcción en la naturaleza como motivos propios del imaginario escandinavo ${ }^{29}$ (intrínsecos entonces en su espíritu sueco pero que reafirmó en sus viajes por el país). Así en su Lilla Hyttnäs en la isla de Lisön, un cuarto de siglo después, Asplund los retoma en una suerte formal de villa rural nórdica que bien podía haber incluido Hazelius en Skansen ${ }^{30}$. La madera de las superficies, el fuego que articula el giro del volumen final hacia un paisaje primitivo que posee un contenido emocional indudable en la vivienda ${ }^{31}$ y establece un nuevo orden desconcertante entre interior y exterior participando, de este modo, el propio fuego del exterior. En un retorno a la arquitectura de las cabañas, Asplund construirá una vivienda en sintonía con las teorías de la salud de la época, en una variación del tema de la cueva, entregándose a la naturaleza en una concepción primitiva del habitar ${ }^{32}$. De esta forma, a pesar de estar entre las rocas y el agua, entre el cielo y la tierra, el emplazamiento no es leído como lugar geográfico, sino como un estado poético-místico sentido en forma de paisaje, recogiendo a los cuatro elementos naturales. Sin embargo, a pesar de reunir todos los elementos, la chimenea, situada en el centro gravitatorio de la casa, coloca al fuego como articulador de la composición, como esencia del hogar. En el clima escandinavo, la capacidad que el fuego tiene para reunir a las personas lo convierte en potencial vertebrador del espacio. Desde tiempos inmemoriales, los hombres buscaron calor y luz alrededor del fuego. Elemento de amistad y fraternidad entre los hombres, la figura geométrica que se forma naturalmente en torno a él es el círculo. De esta forma, en plena madurez, Asplund ha logrado desligarse completamente de lo material, de la forma, para establecer por enésima vez, el encuentro entre el círculo y el rectángulo a través de lo natural, del fuego (figura 7).

29. “...el fuego que para nosotros es tan familiar, donde [el rey] Gustav Vasa y todos sus grandes hombres se han sentado..." BERGH, Richard: "Konst academier" en Efter Lämnade skrifter om konst och annat. Estocolmo: Bonnier, 1921, p. 140. “...el sentimiento del hogar es diferente en una nación que no necesita una chimenea..." Ellen Key citada en FACOS, Michelle: Op. cit. pp. 62-63.

30. Lilla Hyttnäs es la villa de Carl Larsson y su mujer en Dalarna que decoraron ellos mismos y publicaron en Ett hem (Un hogar) en 1899, considerada como el hogar Romántico Nacional por excelencia. Skansen, en Estocolmo en 1891, fue el primer parque etnográfico del mundo al aire libre dedicado a generar un nuevo entusiasmo por la vida popular sueca tradicional. Vid FACOS, Michelle: Op. cit. pp. 71-72 y BLUNDELL-JONES, P.: Op. cit. pp. 196 y ss.

31. Entre los artistas del Romanticismo Nacional, el paisaje nórdico se había convertido en centro de sus estudios. La influencia de la obra de von Heidenstam sobre la vinculación entre paisaje y construcción se explica en WREDE, Stuart: "Paisaje y arquitectura. Clásico y vernacular en Asplund" en CALDENBY, Claes y Olof HULTIN (eds.): Op. cit., pp.: 41-46. La vivienda tiene su antecedente más inmediato en la sportstuga (casa de verano) construida en Stavnäs (1934-37).

32. En 1926, Schindler escribió una serie de artículos en las columnas periodísticas del dr. Lovell, que versaban sobre la arquitectura y la salud (vid GEBHARD, David: Schindler. Barcelona: Orkos-tau, 1979. p. 56). Ejemplos de estas teorías son la vivienda del Dr. Lovell en Newport Beach (1925-26) o la Casa de la Cascada (Wright, 1934-37) donde se funden arquitectura y naturaleza salvaje. Sin embargo estas presentan un orden tecnológico altamente sofisticado lo que representa una negación de la naturaleza en una pretensión de dominio antropológico. No obstante, el Romanticismo Nacional sentía que la inmersión física en la naturaleza fomentaba el primitivismo que ellos consideraban esencial para el habitus sueco. Ya en la década de 1870 el fisiólogo Fritihof Holmgren, el balneologista Carl Curman y el escritor Vyktor Rydberg promovían la salud de la gimnasia, cultura física y baños al aire libre. Adelantándose a las teorías del biólogo alemán Ernst Haeckel en Die Welträthsel (1901). 

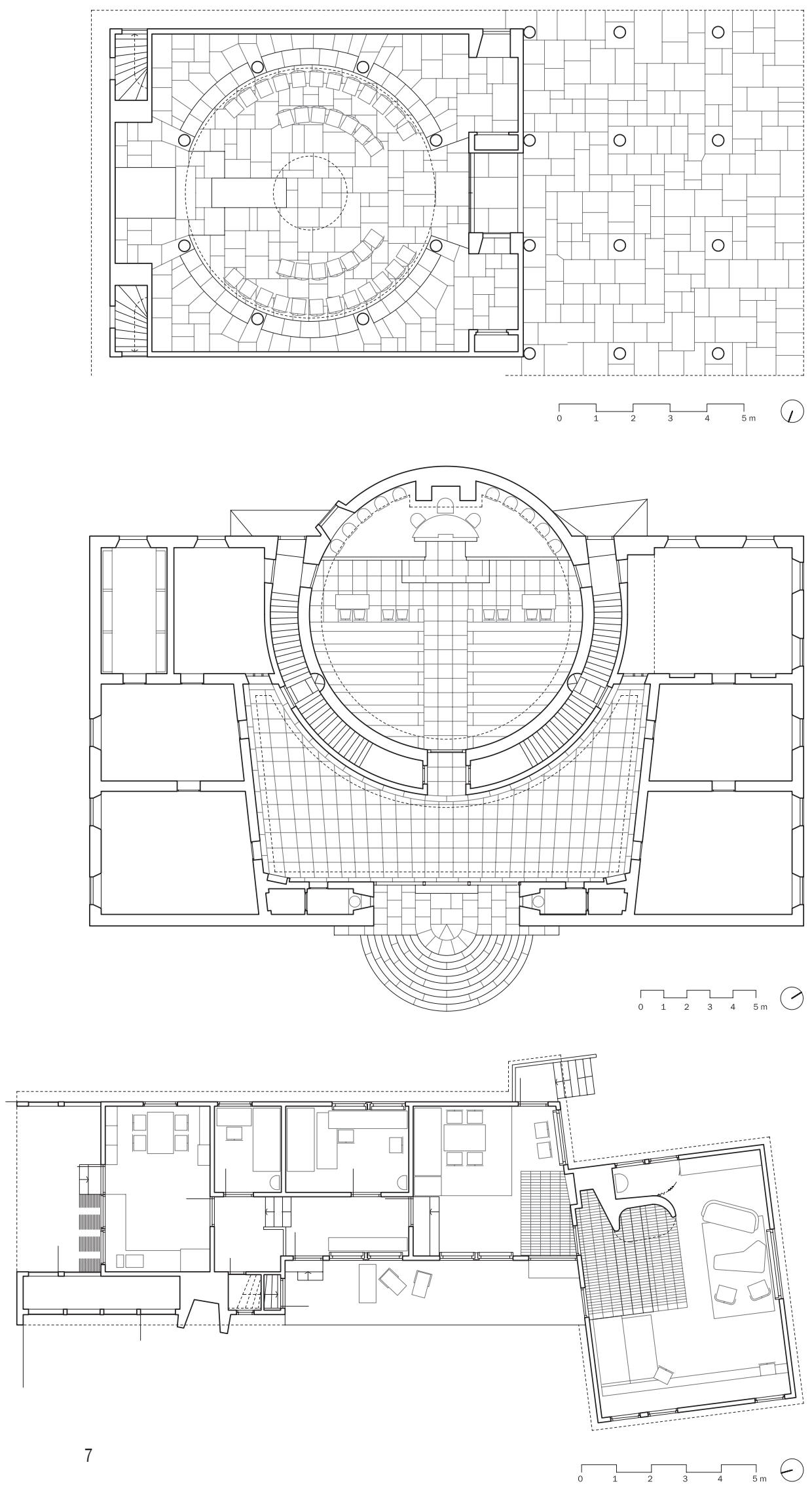

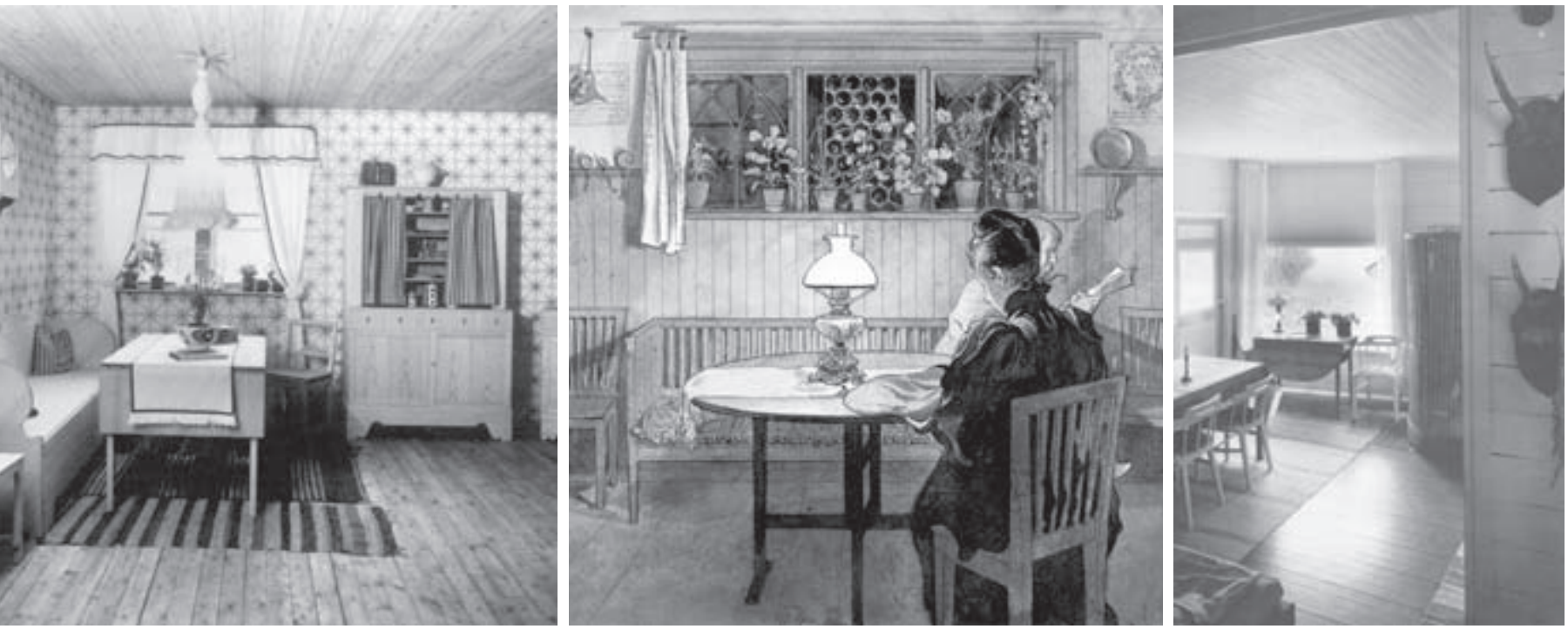

El retorno que, con este gesto, produce Asplund trasciende a los comienzos del siglo XX: en una sociedad estupefacta ante la innovación técnica, Asplund regresa al refugio más primitivo (contra las rocas, como en las cavernas) donde se ampara el hombre para vencer a la obscuridad y al frío, descubre el fuego. Si en la Capilla del Bosque la cuestión geométrica era reducida al encuentro de pirámide y esfera en volumen y al de cuadrado y círculo en planta o en la Biblioteca eran cilindro y prisma, en Stennäs ni siquiera necesitó encontrar formalmente al círculo con el rectángulo, simplemente colocó una chimenea. Una chimenea propia de una villa de Oktorp de 1700, mientras que su interior no deja de ser una evolución de aquellas cocinas que presentó en la Hemutställningen (Exposición del Hogar) de 1917 en Estocolmo (promovida por la entonces Svenska Slöjdföreningen) bajo las teorías y cuadros de Larsson $^{33}$, sobre un verdadero estilo nacional (figura 8).
8. Izquierda: Cocina doméstica (Gunnar Asplund, 1917 - Exposición del Hogar). Centro: "Cuando los niños se han acostado" (Carl Larsson, 1894-96 (Nationalmuseet, Estocolmo). Derecha: Casa de verano (Gunnar Asplund, 1937, Stennäs). El hogar como epítome del arraigo es una figura propia del discurso en el Romanticismo Nacional: Lilla Hyttnäs fue la residencia en la naturaleza de los Larsson y modelo de construcción autóctona que ha llegado a nuestros días; La tradición nominativa de las villas rurales ponía de relieve una identidad de significado metafísico, a la vez estructural y de localización para sus habitantes.

\section{Estocolmo 1930.}

El concepto de verdad en Asplund se desprende desde el artículo que escribió a su vuelta de su viaje de investigación de 1910 en Teknisk Tidskrift A, donde no sólo desarrolló conocimientos sobre superficies y revestimientos, sino que afianzó sus convicciones sobre la honestidad de la obra ${ }^{34}$. Estos principios le acompañaron durante toda su carrera y alcanzaron su culminación en el manifiesto Acceptera (Aceptad) publicado un año después de la Exposición de Estocolmo y un año antes de que los SocialDemócratas llegaran al poder, curiosamente cuando las vanguardias europeas - según Tafuri - habían finalizado: una vez más Suecia parecía llegar tarde ${ }^{35}$. Sin embargo, aunque su verdad tuviera cierta conexión con la de Loos y los modernos, el manifiesto sueco se desligaba de la cuestión formal y de la estandarización promulgando la necesidad del valor sueco en cada creación ${ }^{36}$. En Suecia, el racionalismo nacía de la reacción contra una clase 
social establecida, con sus patrones, hábitos y normas instituidas basadas en influencias externas, mientras que otras clases sociales vivían en condiciones deplorables. Suecia era el país con el mayor grado de hacinamiento de Europa y la promoción estaba en manos privadas. La clase trabajadora de Estocolmo vivía en los años 20 en una vivienda con una habitación, cocina y aseo, con agua caliente, pero sin baño. La conciencia social en la vivienda era algo que se venía desarrollando desde el cambio de siglo en el seno de una cultura igualitaria propia del rettferd sueco $^{37}$. Por aquellos años se había fundado la Hyresgästernas sparkasseoch byggnadsförening (Sociedad para la creación y ahorro de los inquilinos), veinte años después de la Centralförbundet för social arbete (Federación Social del Trabajador) interesadas ambas por las condiciones de vida de los trabajadores. Si desde el punto de vista formal puede parecer que los métodos modernos se empleaban ya en Suecia, aún estaban lejos de la metodología constructiva derivada de la industrialización que no llegó hasta la década de 1950. Así las formas modernas eran adoptadas en Suecia en la medida que los planteamientos eran adaptables al espíritu y comprensión de la problemática escandinava: en correspondencia con el clima, condiciones de salubridad e higiene y el planeamiento del espacio libre y los parques ${ }^{38}$. Con este espíritu, uno de los objetivos y de las doctrinas centrales de la Svenska Slöjdföreningen (Sociedad sueca de artesanía y diseño, cuyo director era Gregor Paulsson desde 1923) en el desarrollo de su Exposición de Estocolmo de 1930, fue que los artistas debían colaborar con la industria para desarrollar productos altamente útiles y dispuestos para la masa. Con estos principios, el 1 de junio de 1927, el Consejo Superior de Artes Suecas encargó a un pequeño grupo formado por Asplund, Lagerström y Paulsson que perfilase las directrices de una exposición en Suecia: dos propuestas fallidas dan paso al viaje por Centroeuropa que Paulsson y Asplund tomarán para desarrollar una idea que satisficiera al comité de la exposición ${ }^{39}$. En 1928, visitaron la Weissenhof-Siedlung, Frankfurt-AmMain y Brno y conocieron a Gropius, Giedion y Pierre Jeanneret entre otros. Finalmente en el invierno de 1928 se aprobó la propuesta que sería construida. No sólo estas estancias influyeron notablemente en el desarrollo de la propuesta: como en Stuttgart, se incluyeron pabellones residenciales que venían a resolver la problemática de la vivienda en Suecia; se amplió el sentido urbano de la propuesta como en Frankfurt y se adoptaron formas modernas para construir los pabellones expositivos don-

33. LARSSON, Carl: Ett hem. Estocolmo: Bonnier, 1899, y FOSSLUND, K. E.: Storgarden: En bok om ett hem. Estocolmo: Wahlström \& Widstrand, 1900. Ambas publicaciones iniciaron el hembygdsrörelse (movimiento aldeano nativo).

34. “...el moderno - y sano - principios de Verdad en arquitectura quiere realmente frustrar toda esta nueva creación de material, pues éste sería sólo copia de la piedra natural y, como tal copia, falsa..." ASPLUND, Erik G.: "Notas sobre un moderno material de fachada alemán" en LÓPEZ PELÁEZ, José Manuel (ed.): Ed. cit. (0.1911). pp.: 18-27.

35. Vid TAFURI, Manfredo: Progetto e utopia. Bari: Laterza, 1973

36. Cf. LOOS, Adolf: "Ornamento y delito" en OPEL, Adolf y Joseph QUETGLAS (ed.): Escritos / 1897/1909. El Escorial: El Croquis, 1993 (0.1908) pp.: $346-355$. En contradicción con el concepto de verdad de los suecos: “...la belleza puede ser lograda de multitud de formas. Pero lo falso y lo deshonesto raramente llegan a ser bellos, a la larga, incluso aun satisfaciendo puntualmente. La belleza no está vinculada a un esquema formal ni funcional. Depende de la forma en que esté hecho el objeto..." ASPLUND, Erik G. et al: Acceptera. Estocolmo: Tiden, 1931, p. 103. Para ver un desarrollo de Asplund del mismo concepto y en contra de la estandarización vid ASPLUND, Erik G.: "Nuestro concepto arquitectónico del espacio" en LÓPEZ PELÁEZ, José Manuel (ed.): 0p. cit. pp.: 170-184.

37. El representante de SDP (Partido Social-Demócrata) Per Albin Hansson en 1928 en sesión parlamentaria expresaba este sentimiento: “...el marco básico del hogar es cooperación y un sentimiento de pertenencia. El buen hogar no conoce ningún privilegio ni prejuicio; no tiene miembros favoritos ni abandonados. Alli, un miembro no mira a otro altivamente; alli, nadie busca sacar provecho a expensas del otro; el fuerte no oprime ni roba a los débiles. En el buen hogar igualdad, consideración, cooperación y servicialidad son las reglas. Adaptado a las más grandes "casas populares", esto significaría la disolución de todas las diferencias sociales y económicas que dividen actualmente a los ciudadanos en privilegiados y desfavorecidos, dominantes y dependientes, ricos y pobres, los que tienen y los que no tienen, saqueadores y saqueados..." (de las sesiones parlamentarias de los años 20 en HOLMBERG, Per e Ingemar LINDBERG: En Bok om rättvisa. Estocolmo: Brevskolan L0, 1993)

38. Para un desarrollo de la cuestión vid RUDBERG, Eva: The Stockholm Exhibition 1939. Modernism's breakthrough in swedish architecture. Estocolmo: Stockholmia Förlag, 1999, pp. 25-32.

39. Para una explicación de estas propuestas vid. PAULSSON, Gregor: Upplevt. Estocolmo: Experiences, 1974, pp. 25 y ss. 

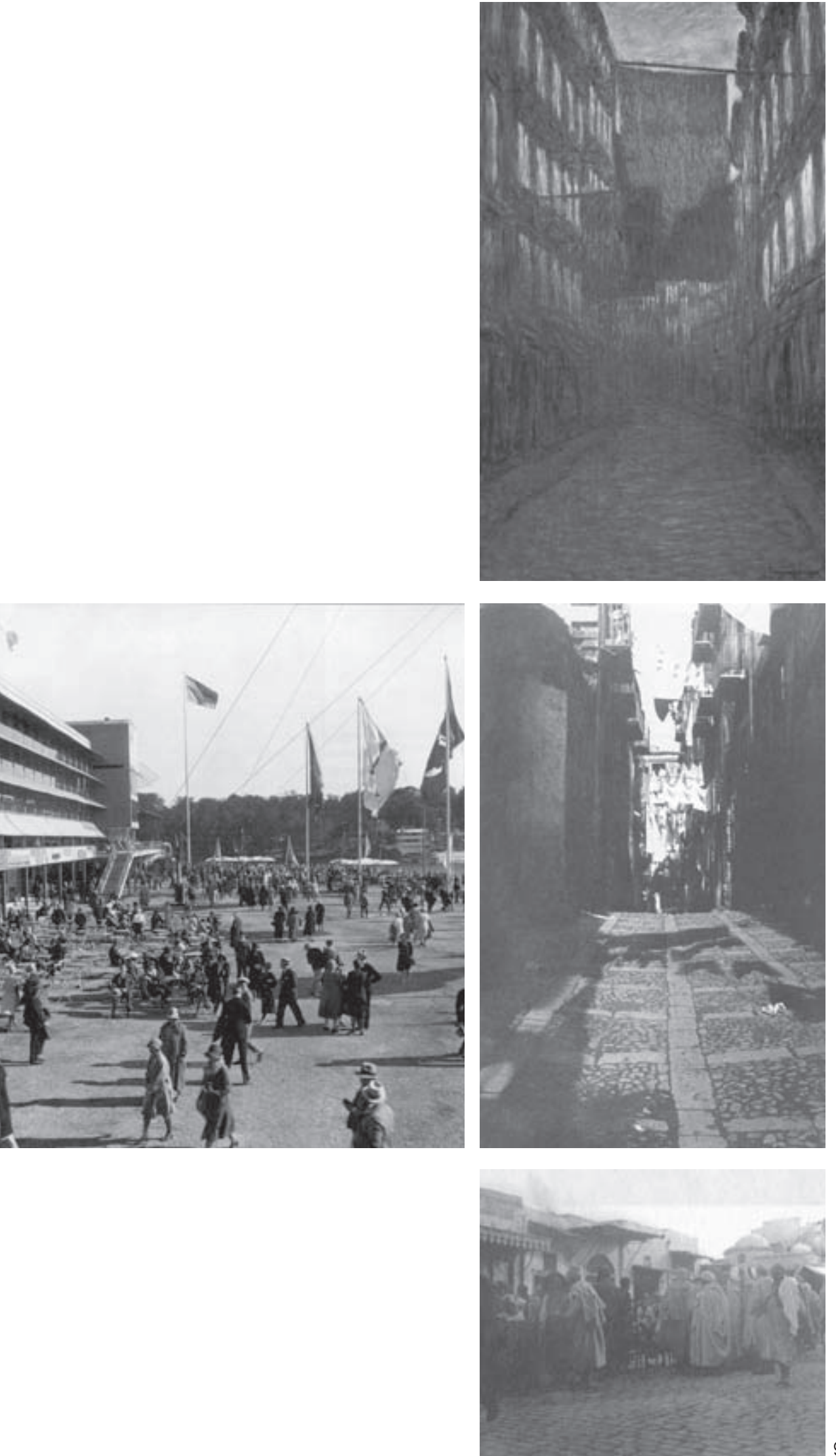

9. Izquierda: Restaurante Paradiset (Gunnar Asplund, 1930) Arriba: "Österlanggatan" (Eugene Jansson, 1904, Thielska Galleriet). Centro: Fotografía de Italia (Gunnar Asplund, 1914). Abajo: Fotografía de Túnez (Gunnar Asplund, 1914). Asplund registró instantáneas de las ropas y banderas en las calles de Italia, al igual que Jansson hizo con la tradición sueca de las banderas de las tabernas marineras y las ropas de los marineros al caer la tarde en los barrios mercantes. Además de las banderas, el uso del espacio exterior de Túnez, en el contacto con la naturaleza estival sueca de Djurgarden presente en la Exposición de 1930.

10. "Fin de los funkis" (Carl Jacobson, 1930 - Dagens Nyheter, 29/9/30). Con el cierre de la Exposición de 1930, Jacobson muestra el reflejo de las críticas en la caricatura donde los artistas que denigraron a la exposición (entre ellos Östberg, profesor de Asplund en la Klara Skola y Milles, que realizó el Ángel de la Muerte en la Capilla del Bosque para Asplund) transportan los restos de la Exposición sobre los que se sienta Paulsson, su director. Frente a esto, Asplund, Markelius y Ahre (los arquitectos protagonistas) Iloran la situación mientras que, al otro lado, Söderlund representa el coste económico que le supuso a la ciudad. 


\section{finis funkis - många sörja, andra glädjas.}

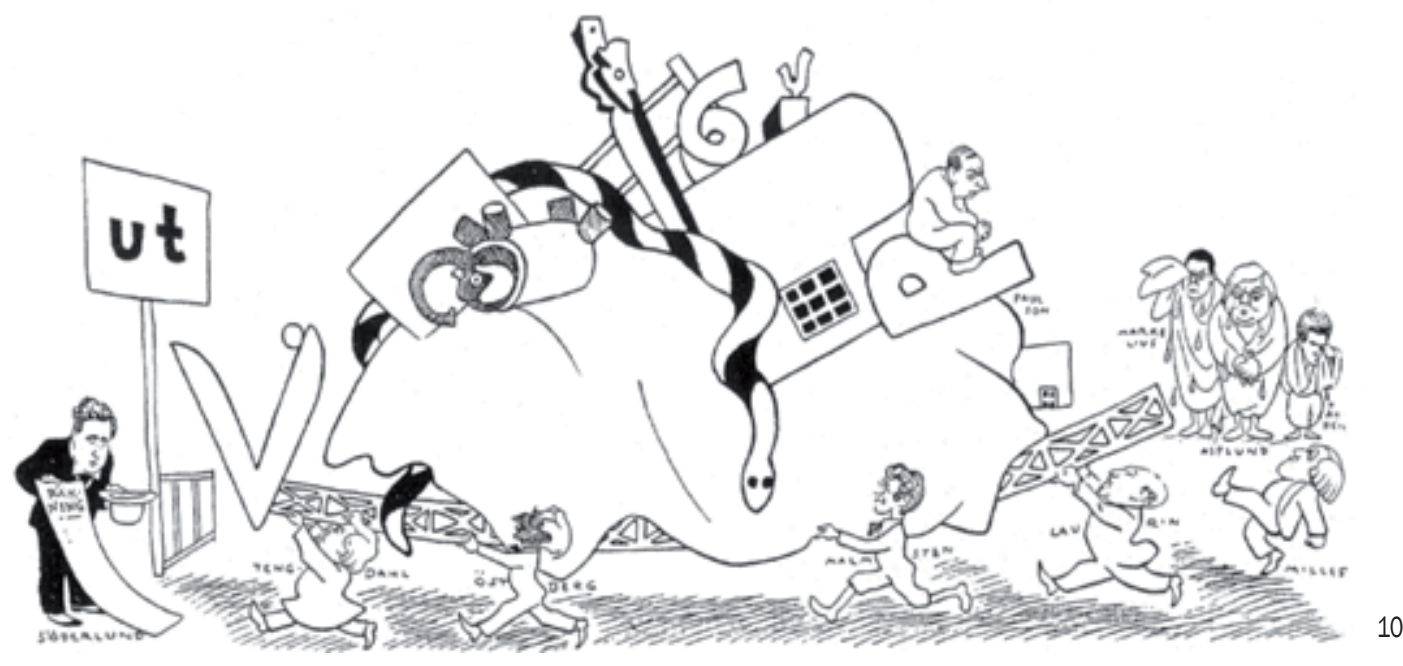

de incluso una base constructivista radica en la materialización de la propuesta ${ }^{40}$. Sin embargo, la asunción formal racionalista tiene más que ver con la formación de un telón neutro y aséptico que permitiera dar paso a la verdadera esencia de la muestra: la calle (Corso) era la verdadera exposición e inclusive los pabellones se habrían a ella. El espíritu nórdico primitivo de habitar en la naturaleza cobraba importancia desde la propia ordenación: a un lado del Corso se construye, al otro se deja libre la vista al agua y a la vegetación intacta. Desde la otra orilla el agua es el espejo de la arquitectura. La escala de la arquitectura construida en las dos orillas enfrentadas del canal acota la dimensión del ancho del agua. Asplund, mediante el empleo de la luz del verano sueco, el color de las banderas, el aire que las movía y les regalaba cualidad formal, la comunicación, las flores y el agua, el discurrir por el recinto... creó una estructura inmaterial entre los cuerpos geométricos, una interactuación imperceptible que guarda estrechas relaciones con el subconsciente humano. De algún modo emplea lo construido, no como artificio, sino como exaltación de lo natural, otorgándole forma y proporción. Aunque sus viajes por Centroeuropa con Paulsson se han visto como determinantes para el proyecto de la exposición, el origen está más próximo a Túnez y el comercio y vida en el espacio público exterior que le llevó a la construcción en la naturaleza de los románticos suecos; a las banderas y carnavales de Italia que ensalzaron a las festividades del verano rural sueco y las tradiciones urbanas de los barrios marineros ${ }^{41}$ (figura 9).

Así la figuración moderna alcanzada por Asplund en la Exposición de 1930, sólo fue eso: formas que se adaptaban a las necesidades en la medida que resolvía cuestiones inherentes al patrón escandinavo y al motivo del proyecto ante las críticas recibidas por sus propios compatriotas y colegas: la prensa socialista influida por la URSS que veían a la modernidad como expresión del capitalismo de la burguesía; la prensa conservadora que no la consideraba suficientemente sueca; sus colegas Boberg y Clason; incluso desde el interior de la Svenska Slöjdföreningen, donde se creía que los productos industriales habían sido mejor tratados que los artesanos etc. Sin embargo la idea de crear un e-nlace orgánico entre cultura y naturaleza, de prever la integración de la arquitectura en la naturaleza y la historia para el encuentro del sueco medio en un lugar reconocible para él, son las bases de la arquitectura y espíritu nórdico tradicional que Asplund había llegado a dominar. El encuentro entre estructura topográfica, ecológica y sociológica de un territorio y sus habitantes provocó que la Exposición fuera visitada por cuatro millones de personas cuando la población total del país en 1930 era de seis millones de habitantes (figura 10).

40. Aunque se ha argüido mucho sobre el fundamento constructivista (derivado de la Modernidad) que radica no sólo en la formalización de los pabellones, sino en la disposición de carteles, quioscos, letreros, la torre de Lewerentz... Cf. FRAMPTON, Kenneth "Estocolmo 1930. Asplund y la herencia de los Funkis". En CALDENBY, Claes y Olof HULTIN (eds.): Op. cit., pp.: 35-40. Ya en 1800 la mayoría de los suecos sabían leer y escribir, ya que desde el s. XVII los párrocos examinaban anualmente a los adultos en las lecturas religiosas, esto provocó que en el XIX Suecia, aunque fuera una sociedad eminentemente agraria, tuviera el índice de alfabetización más alto del continente. Por lo que al entrar en el s. XX, este tipo de publicidad y mensajes escritos, propios de la formalización constructivista tuviera una gran acogida entre el público sueco.

41. Para ver un desarrollo de su viaje por Italia como fuente de la exposición vid FANT, Ake: Op. cit. 
Por esto, no debemos ver una adscripción de Asplund al racionalismo, del que nunca fue coincidente ni partícipe. Curiosamente lo efímero de la Exposición vino a coincidir con la duración de la obra "moderna" de Asplund que prácticamente duró lo que la muestra. Tampoco se puede decir que viniera a definir una etapa de madurez del arquitecto, sino la extremada sensibilidad de Asplund para hacer converger arquitectura, naturaleza y hombre (con todas las necesidades que llevan estas dos últimas) que le hizo comprender qué arquitectura era la adecuada para resolver una cuestión más. Catálogo y clasificación, es decir, el establecimiento de signos reconociblemente similares en distintas obras que pudieran ser identificables bajo una envolvente figurativa que designe los patrones de un movimiento unificador son - en Asplund - cuestiones bizantinas. Su lenguaje fue un acto honesto desprendido de lo meramente técnico, funcional o exclusivamente simbólico. En sus obras los elementos, las articulaciones, los volúmenes y los espacios encerrados en ellos tienen una construcción que abarca la amplitud del mundo. Una mirada estereoscópica de la acción de construir, porque no sólo construía edificios, creaba un mundo... En Asplund, el asunto de las influencias es tan volátil, que más vale desplazarlo hacia el territorio de las correspondencias, de manera que las obras surgen de una matriz común, de una cierta idea de forma de vida escandinava, independiente a su fecha de producción. De esta forma, el viaje, en génesis: la influencia extranjera, es adoptada en tanto la conciencia nacional intrínseca al nórdico - interiorizada de forma inconsciente - lo permite. En este sentido, la obra de Asplund pertenece a la tradición mencionada sin dejar de compartir con ella una experiencia severamente contemporánea. El viaje es entonces, tan revelador de las tendencias de la época como reafirmador de la propia nacionalidad. Así, en el acuerdo de las fuentes exteriores de inspiración con las misiones específicas que le condujeron a la naturaleza del lugar y el espíritu nórdico se situó la obra de Asplund, legándonos cientos de cuestiones que, como en cada uno de sus proyectos, no nos dejan sino más años de preguntas. 


\section{Bibliografía}

AA.VV.: Asplund, 1885-1940. Arsbok. Estocolmo: Arkitekturmuseet, 1986.

ALHBERG, Hakon: Gunnar Asplund, Arquitecto. 1885-1940. Madrid: COAAT, 1982 (0. 1943)

ASPLUND, Erik Gunnar, et al: Acceptera. Estocolmo: Tiden, 1931.

BERGH, Richard: "Konst academier" en Efter Lämnade skrifter om konst och annat. Estocolmo: Bonnier, 1921.

BLUNDELL-JONES, Peter: Asplund. NY: Phaidon, 2006.

CALDENBY, Claes y Olof HULTIN (eds.): Asplund. Barcelona: GG, 1988 (0. 1983).

CALDENBY, Claes.; Joran LINDVALL y Wilfried WANG (eds.): Sweden. 20th-century architecture. NY: Prestel, 1998.

CORNELL, Elias: “El Cielo como una Bóveda”, en ALHBERG, H.: Gunnar Asplund, Arquitecto. 1885-1940. Ed. cit. (0. 1961).

DONNELLY, Marian C.: Architecture in the scandinavian countries. Boston: Massachusetts Inst. of Technology, 1992.

ENGFORS, Christina: E.G.Asplund: Architect, friend and colleague. Estocolmo: Arkitektur Förlag, 1990.

LANE MILLER, Barbara: National romanticism and modern architecture in Germany and scandinavian countries. Cambridge: Cambridge Un. Press, 2000.

LARSSON, Carl: Ett hem. Estocolmo: Bonnier, 1899.

LÓPEZ PELÁEZ, José Manuel: La Arquitectura de Gunnar Asplund. Barcelona: Fundación Caja de Arquitectos, 2002.

LÓPEZ PELÁEZ, José Manuel y Luis Moreno MANSILLA (eds.): Escritos 1906-1940. Cuaderno de Viaje a Italia de 1913. El Escorial: El Croquis, 2002.

LYN, Francis E.: “Mediterranean resonances in the work of Erik Gunnar Asplund” en LEJEUNE, Jean Françoise y Michelangelo SABATINO (eds.): Modern architecture and the vernacular dialogues and contested identities. NY: Routledge, 2010.

FACOS, Michelle: Nationalism and the nordic imagination. Swedish art of the 1980s. Londres: Un. California Press, 1998.

JOSEPHSON, Ragnar.: Nationalism och Humanism, Estocolmo: Bonnier, 1935.

KENT, Neil: The soul of the north. A social, architectural and cultural history of the Nordic Countries. Londres: Reaktion Books, 2001 (0.2000).

MATTSON, Helena y Sven 0. WALLENSTEIN: 1930-1931. Den svenska modernism vid vägskälet. Estocolmo: AXL, 2009.

PAULSSON, Gregor: Upplevt. Estocolmo: Experiences, 1974.

RUDBERG, Eva: The Stockholm Exhibition 1939. Modernism's breakthrough in swedish architecture. Estocolmo: Stockholmia Förlag, 1999.

VARNEDOE, Kirk (ed.): Northern light. Realism and symbolism in scandinavian painting. NY: Brooklyn Museum, 1983.

WREDE, Stuart: La arquitectura de Erik Gunnar Asplund. Barcelona: Júcar Universidad, 1992 (0.1980).

ZEVI, Bruno: Erik Gunnar Asplund. Buenos Aires: Infinito, 1957.

Pablo López Santana (Alicante, 1981) Arquitecto (E.T.S.A. de Sevilla, 2005). Socio-fundador de SVAASCP y del grupo multidisciplinar Escultura. Premios en concursos: 2005: finalista XXIII Dragados PFC. 2007: finalista Ordenación ARI-DS-01; 1er. Accesit Rehabilitación Polígono Sur. 2008; 1er. Premio Mejor Edificio Residencial de Málaga. 2009: 1er. Premio Cdad. Dpva. R. Betis. Vinculación a la Universidad de Sevilla: Colabora con el Grupo de Investigación HUM-632 (Universidad de Sevilla); Asistente Honorario Dpto. Proyectos Arq. (E.T.S.A. de Sevilla). 2008/09:Máster en Ciudad y Arquitectura Sostenible (E.T.S.A. de Sevilla); Profesor contratado (Dpto. Proyectos Arquiotectónicos, E.T.S.A. de Sevilla). 2009: Profesor invitado Universidad de Sevilla. 2010: Codirector proyecto de investigación Topografías de la percepción, expuesto en WL (Sevilla) y LABoral CAC (Gijón); Director serie de cortometrajes experimentales Sentidos. Últimas Publicaciones: Serendipities, Oxymorons, Palindromes and Other Issues Related to Dublin Heritage (UPM, 2009) Naturaleza y Esperanza (TICCHI, 2009) Sísifo en Mont Veadoux (TICCHI, 2009). 


\section{Autor imagen y fuente bibliográfica de procedencia}

Información facilitada por los autores de los artículos: página 18, 1 (FINE LICHT, K.: The Rotunda in Rome. A study oh Hadrian's Pantheon. Koblnhavn, Jutland Archeological Society, 1966, p. 238); página 19, 2 (SCHRAUDOLPH, E: Der Ruhm des Pantheon. Berlin: Estaatliche Museum zu Berlin, 1992, p. 37), 3 ( http://www.info.roma.it/foto/roma_sparita/ grandi/221.jpg, consulta junio 2010); página 20, 4 y 5 (Francisco J. Montero Fernández); pagina 22, 6 (Francisco J. Montero Fernández); página 24, 7 (dibujo Francisco J. Montero Fernández, 2010), 8 (BOESIGER W.: Le Corbusier. Obra completa 1957-1965. volumen 7. Zürich,: Girsberger, 1965-1985, pp.182); página 25, 9 (dibujo Francisco J. Montero Fernández, 2010); página 26, 10 (dibujo Francisco J. Montero Fernández, 2010); página 27, 11 y 12 (dibujo Francisco J. Montero Fernández, 2010); página 29, 13 y 14 (Francisco J. Montero Fernández); página 31, 15, a 17 (Francisco J. Montero Fernández); página 35, 1 (Nárödni Galerie, Praga); página 38, 2 (SEKLER, Eduard: Josef Hoffmann: the Architectural Work. New Jersey: Princeton, 1985, p. 59), 3 (Nárödni Galerie, Praga), 4 (Lyon: L'Aventurine, 2006, p.16); página 39, 5 (Lyon: L'Aventurine, 2006, p.20 y p. 104); página 40, 6 (publicado por Meda Mladek en Frank Kupka. Colonia: Galerie Gmurzynska, 1981, pp. 59 y 53); página 41, 7 (publicados por Meda Mladek en Frank Kupka. Colonia: Galerie Gmurzynska, 1981, p. 43); página 42, 8 (publicado en VV.AA.: František Kupka, Barcelona: Fundació Joan Miró, 2009, p. 66); página 43, 9 (publicado en VV.AA.: František Kupka, Barcelona: Fundación Joan Miró, 2009, p. 44); página 44, 10 (Fotografía de Dos\&Bertie Winkel); página 45, 11 (publicado en WILLIAM, David: Naval Camouflage 1914-1945. Annapolis: Naval Institute Press, 2001, p. 134); página 53, 1 (CFLC 5845); página 56, 2 (CFLC 2029); página 57, 3 (CFLC. L4(19) 95); página 59, 4 (CFLC 2856); página 64, 1 (VARNEDOE, Kirk (ed.): Northern light. Realism and symbolism in scandinavian painting. NY: Brooklyn Museum, 1983); página 65, 2 (Archivo Larsson del Nationalmuseum, Estocolmo); página 66, 3 (Arriba: CALDENBY, Claes; Joran LINDVALL y Wilfried WANG (eds.): Sweden. 20th-century architecture. NY: Prestel, 1998. Abajo: Archivo fotográfico de SVAASCP); página 68, 4 (Arriba: LEJEUNE, Jean-Françoise y Michelangelo SABATINO (eds.): Modern architecture and the vernacular dialogues and contested identities. Nueva York: Routledge, 2010. Abajo: BLUNDELL-JONES, Peter: Asplund. NY: Phaidon, 2006); página 70, 5 (dibujos, archivo SVAASCP, 2010); página 72, 6 (Izquierda.: BRUMMER, Hans H.: Prins Eugen - Minnet av ett landskap. Estocolmo: PE Waldemarsudde, 1998. Derecha: KAWASHIMA, Yoichi (ed.): E.G. Asplund. Tokio: TOTO, 2005); página 73, 7 (dibujos archivo SVAASCP, 2010); página 74, 8 (Izquierda: Archivo Asplund del Arkitekturmuseet, Estocolmo. Centro: LINDWALL, Bo: Carl Larsson. Aquarelles. París: Bib. de l'image, 1994. Derecha: CRUICKSHANK, Dan (ed.): Erik Gunnar Asplund. Londres: AJ, 1988); página 76, 9 (Izquierda: Archivo Asplund del Arkitekturmuseet, Estocolmo. Arriba: VARNEDOE, Kirk (ed.): Northern light. Realism and symbolism in scandinavian painting. NY: Brooklyn Museum, 1983. Centro: Archivo Asplund del Arkitekturmuseet, Estocolmo. Abajo: Archivo Asplund del Arkitekturmuseet, Estocolmo); página 77, 10 (Archivo Asplund del Arkitekturmuseet, Estocolmo); página 84, 1 (Hugo Häring Archiv, Stiftung Archiv der Akademie der Künste, Berlin, ᄂ 15/4); página 85, 2 y 3 (dibujos Rafael Schlatter Martínez, 2010); página 86, 4 (dibujos Rafael Schlatter Martínez, 2010); página 87, 5 (Hugo Häring Archiv, Stiftung Archiv der Akademie der Künste, Berlin, ᄂ 18/7), 6 (dibujos Rafael Schlatter Martínez, 2010); página 88, 7 (BLUNDELL JONES, Peter: Hugo Häring, the Organic versus the Geometric. Stuttgart \& London: Axel Menges, 1999); 8 (Hugo Häring Archiv, Stiftung Archiv der Akademie der Künste, Berlin); página 89, 9 (KAHN, Fritz: Anatomie, Biologie, Physiologie und Entwick-lungs-geschichte des Menschen. Vol. 2, Stuttgart, 1926); página 92, 10 (Hugo Häring Archiv, Stiftung Archiv der Akademie der Künste, Berlin, ᄂ 96/1); página 97, 1 (fotografía Anna Armstrong); página 98, 2 (fotografía Anna Armstrong); página 99, 3 (Archivo Sir Owen Williams and Partners); página 100, 4 y 5 (fotografía y dibujo Teresa Rovira Llobera); página 101, 5 (Archivo Sir Owen Williams and Partners); página 102, 6 (fotografía Archivo Sir Owen Williams and Partners. Dibujo Teresa Rovira Llobera); página 103, 7 (fotografía: Raphl Morris. Dibujo Teresa Rovira Llobera); página 105, 8 (fotografía Joseph McGarraghy); página 106, 9 (Archivo Sir Owen Williams and Partners. Fotografía Duncan Campbell); página 107, 10 (Archivo Sir Owen Williams and Partners); páginas 121 a 132, 1 a 12 (Fondation Le Corbusier, FLC - ADAG P. 11, rue Berryer, 75008 París); página 137, 1 (Los Angeles County Museum of Art); página 139, 2 (C 1924 Mezhrabprom-Rus, ( 2004 RUSCIC0), 3 (@ 1929 Universum Film AG); página 140, 4 (Metropolis @ 1926 Universum Film AG); página 142, 5 (@ 1956 Turner Entertainment Co.); página 143, 6 (Star Wars 1977 Lucasfilm Ltd., Alien @ 1979 Twentieth Century Fox Film Corporation, Stargate Atlantis @ 2004 MGM Global Holdings Ltd.); página 144, 7 (๔ 1968 Turner Entertainment Co.); página 146, 8 (THX 1138 @ 1970 Warner Bros. Entertainment Inc., Blade Runner @ 1982 The Blade Runner Partnership), 9 (Solaris ( 1972 Mosfilm); página 147, 10 (๔ 1968 Turner Entertainment Co); página 148, 11 (C 1980 Lucasfilm, Ltd); página 151, 12 ("Alien's cockpit» @ 1978 HR Giger, obra n. 377, acrílico sobre papel, 70x100 cm. Alien ( 1979 Twentieth Century Fox Film Corporation.); página 152, 13 (Dune ㄷ 1984 Dino de Laurentiis Corporation. Brazil (C) 1985 Universal Studios); página 153, 14 (Solaris y Stalker @ 1972 y 1979 Mosfilm) 